\title{
Imagem e forma: dois aspectos dos limericks de Edward Lear
}

Dirce Waltrick do Amarante

Para muitos estudiosos a literatura nonsense inglesa nasceu em 1846, com a publicação do livro A Book of Nonsense, do

escritor, desenhista e pintor inglês Edward Lear (1812 - 1888). $\bigcirc$ termo nonsense, que identifica o gênero, foi tomado de empréstimo, aliás, do título desse livro, que reúne 36 poemas humorísticos de Lear, acompanhados de ilustrações do próprio autor.

A respeito das ilustrações de Lear, cabe aqui lembrar que, antes de se tornar escritor, o artista inglês havia se dedicado ao desenho e à pintura. Essas atividades Lear aprendeu em casa, com as irmãs mais velhas, que foram as responsáveis pela sua educação (em razão da saúde debilitada - sofria de bronquite, asma, etc. -, Lear freqüentou pouco a escola). Cedo, porém, transformou essas habilidades artísticas em ofício.

Aos dezoito anos, já com alguma experiência como desenhista (havia colaborado na Illustrations of British Ornithology Ilustrações da Ornitologia Britânica), publicou sozinho seu primeiro livro de ilustrações: Illustrations of The Family of Psittacidae, or Parrots (llustração da família dos Psitacídeos, ou Papagaios (1832)). O livro foi um sucesso "ornitológico e artístico, mas não financeiro". ' Tornou-o, entretanto, conhecido como ilustra- 
AMARANTE, Dirce Waltrick do. Imagem e forma: dois aspectos dos limericks...

dor de história natural e isso the rendeu algumas propostas de trabalho.

Aos dezenove anos foi contratado para fazer as ilustrações dos espécimes do zoológico de Lord Stanley, em Knowsley Hall. Na propriedade de Lord Stanley, Lear começou a escrever seus primeiros poemas cômicos, compostos apenas de quatro ou cinco versos (conforme disposição gráfica), acrescentando-lhes seus desenhos, para divertir as crianças que viviam no local: "There was an Old Man of Peru,/ Who never knew what he should do;/ So he tore off his hair, and behaved like a bear,/ That intrinsic Old Man of Peru" (tradução possível: "Havia um Velho Senhor de Agadir/ Que nunca sabia como agir;/ logo ele arrancou o cabelo, e se portou como um camelo/ Esse intrínseco Senhor de Agadir"). ${ }^{2}$

Posteriormente, esses poemas cômicos, que Lear chamava simplesmente "nonsense", foram denomindos limericks. Ninguém sabe ao certo o porquê dessa denominação. ${ }^{3}$ Acredita-se, todavia, que ela esteja relacionada provavelmente ao ritmo dos poemas, que "deve ter-se originado de alguma melodia ou dança popular, talvez proveniente do condado de Limerick, na Irlanda" ${ }^{4}$

Os primeiros limericks de Lear só foram publicados mais de uma década depois de tê-los escritos em Knowsley Hall. Durante esse tempo, continuou pintando, dessa vez as paisagens que via nas muitas das viagens que fez (ao contrário de Lewis Carroll, que pouco saiu de sua terra natal, Lear foi um "turista inveterado, viajou para a Índia, Ceilão, Egito, Arábia, Ásia Menor, Síria, Palestina, Itália e Grécia e passou parte de sua vida longe de sua nativa Inglaterra"). ${ }^{5}$

Embora Lear tivesse lecionado desenho até mesmo à Rainha Vitória, nunca conseguiu o reconhecimento que desejava como pintor e desenhista.

A fama e o dinheiro chegaram, efetivamente, com a sua poesia. Seus primeiros limericks foram publicados em 1846. Em 
1867 saía a $17^{a}$ edição do livro A Book of Nonsense, já com muitos acréscimos. Uma resenha sobre o trabalho dizia que: "Nunca antes se publicou um livro tão exatamente em sintonia com o pensamento das crianças quanto este; o admirável artista que o produziu sem dúvida se orgulha mais da alegria que esses desenhos e versos absurdos propiciam a um milhão de crianças do que dos vigorosos quadros com os quais encantou o mundo artístico."6

A obra de Edward Lear abrange, desse modo, além de seus textos nonsense (que incluem os limericks, as canções e estórias, a botânica nonsense, o alfabeto nonsense, entre outros), sempre acompanhados de desenhos do autor, também livros de ilustrações de bichos e de viagens e "cerca de trezentas pinturas a óleo e aquarelas, algo entre trinta mil (a estimativa é dele) e dez mil (a de seus biógrafos)" ${ }^{\prime 7}$

No tocante às ilustrações dos limericks, Lisa Ede, estudiosa da literatura nonsense, opina que "muito da riqueza da experiência de leitura dos limericks de Lear pode ser determinada por suas ilustrações". 8 Segundo Ede, a interação entre desenho e texto é, aliás, "um elemento fundamental na criação de significados".

Além disso, as ilustrações do artista inglês "expõem muitas vezes os processos básicos ou os princípios organizacionais de trabalho no mundo dos limericks" ${ }^{10}$ Isso acontece quando, por exemplo, o desenho registra o momento da metamorfose de um personagem, que se torna parecido com o animal com o qual está envolvido (cabe aqui lembrar que os limericks se dividem em dois grupos temáticos principais, os que têm como objeto animais e os que têm como tema a alimentação). ${ }^{11} \mathrm{O}$ registro dessa imagem leva o leitor a se convencer de que está num "novo mundo", onde as mudanças de formas e de relações são constantes. Assim, vejamos abaixo a ilustração que acompanha o limerick sobre um velho cidadão "do sul" que dançou com uma varejeira-azul (na minha tradução): "There was an old person of Skye,/ Who 
AMARANTE, Dirce Waltrick do. Imagem e forma: dois aspectos dos limericks...

waltz'd with a Bluebottle fly:/ Thy buzz'd a sweet tune, to the light of the moon,/ And entranced all the people of Skye" ("Havia um velho cidadão do sul,/Que valsou com uma varejeira-azul:/ Eles zuniram uma doce melodia, à luz do meio-dia/ E extasiaram todas as pessoas do sul")

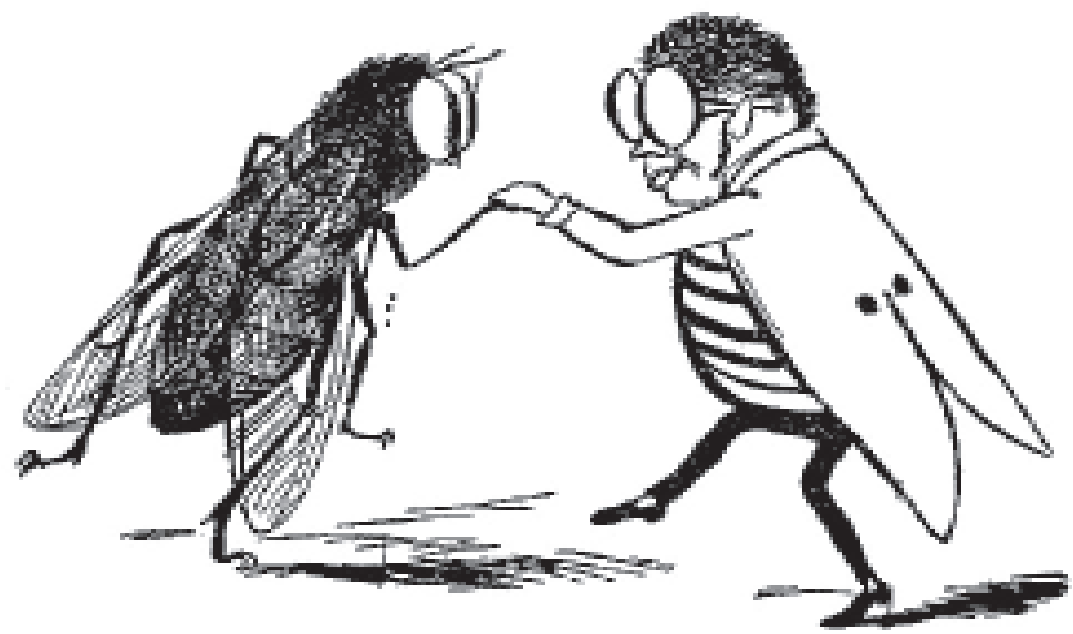

There was an old person of Skye

As ilustrações de Lear também podem servir para complementar e esclarecer os poemas, outras vezes, porém, os desenhos parecem contradizer o texto, enfatizando ainda mais o mundo "absurdo" do nonsense. Cito, como exemplo, um poema sobre um "senhor do cerrado" (na minha tradução) que, por engano, foi "colocado" no forno por sua mulher. Assim se lê no poema, mas, na ilustração, o aspecto determinado da mulher revela que não se trata de um equívoco, mas de um ato deliberado e criminoso da esposa cruel: "There was an Old Man of Peru,/ Who watched his wife making a stew;/ But once, by mistake, in a stove she did bake/ That unfortunate Man of Peru" ("Havia um Velho Senhor do Cerrado,/ Que via sua mulher fazer um guisado/ Mas 
um dia ela se enganou e no forno colocou/ Esse desafortunado Senhor do Cerrado").

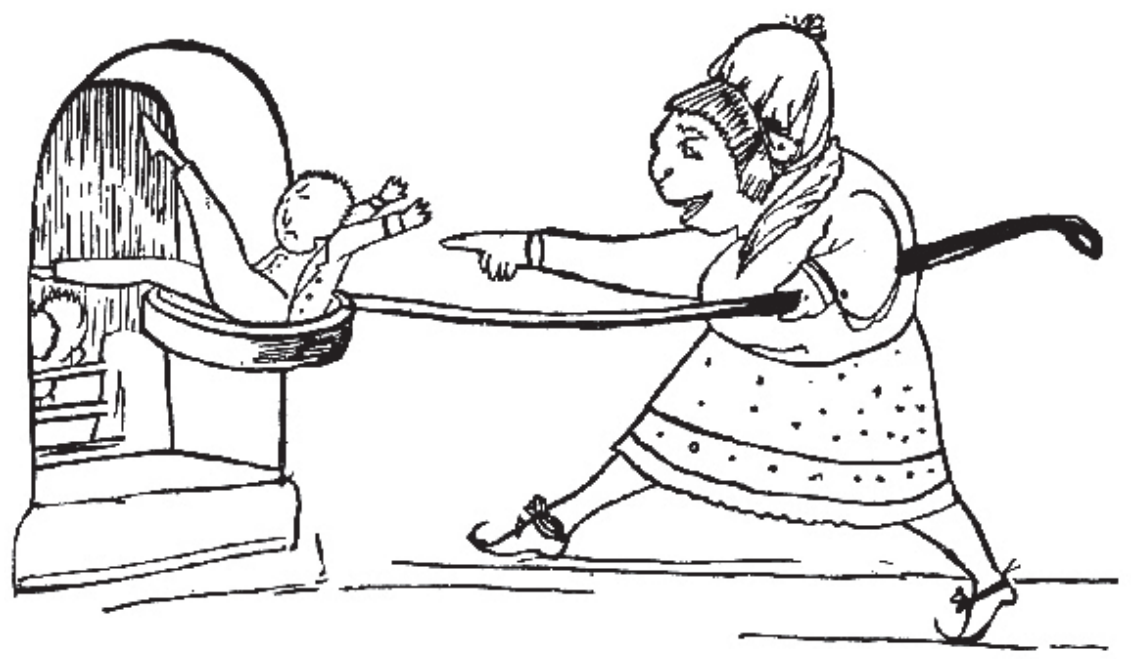

There was an old man of Peru

Outro aspecto a se considerar nos desenhos de Lear é a multiplicação de uma mesma de imagem (como num jogo de espelhos) e a presença de grupos de pessoas. Essas ilustrações têm por objetivo enfatizar geralmente uma situação infindável (no caso da multiplicação de imagens) ou acentuar a disputa entre um grupo de pessoas e um indivíduo (o grupo de pessoas está muitas vezes atacando fisicamente o indivíduo. A coletividade, nos limericks de Lear, age, aliás, como um instrumento repressor contra a individualidade). ${ }^{12}$ Exemplifico esse aspecto da ilustração de Lear com as gravuras abaixo, que ilustram os seguintes poemas: "There was an Old Man of Apulia,/ Whose conduct was very peculiar;/ He fed twenty sons upon nothing but buns,/ That whimsical Man of Apulia" ("Havia um Velho Senhor de Madagascar,/ Cuja conduta era bastante peculiar;/ Alimentou vinte irmãos somente com grãos,/ Esse extravagante Senhor de Madagascar"). 


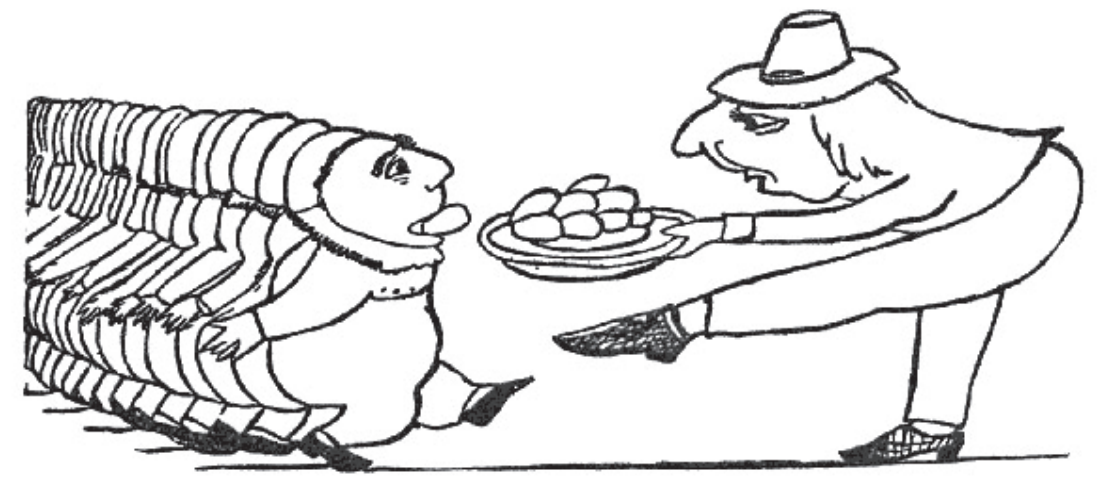

There was an old man of Apulia

"There was an old person of Sark,/ Who made an unpleasant remark;/ But they said, "Don't you see what a brute you must be,/ You obnoxious old person of Sark!"" ("Havia um velho cidadão de Ontário,/ Que fez um desagradável comentário;/ Mas eles disseram rapidamente, "Não vês que tu és um demente,/ Obnóxio cidadão de Ontário!").

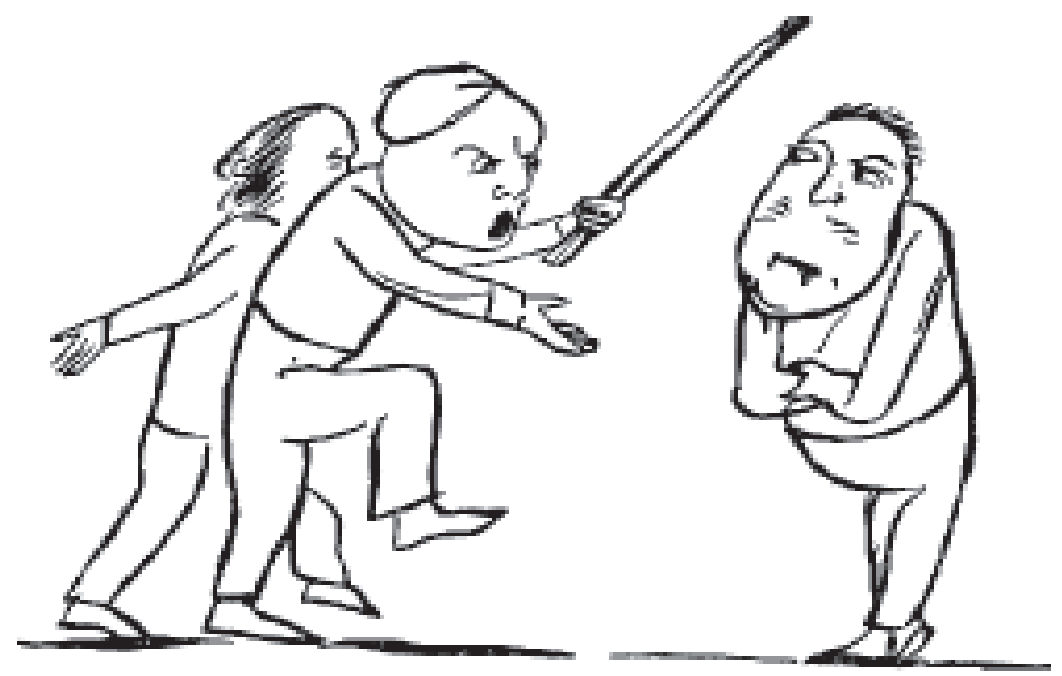

There was an old person of Sark 
Tão importante quanto a ilustração é a forma dos limericks: nestes, assim como nos demais poemas nonsense, a forma atua como uma "camisa de força", ${ }^{13}$ não permitindo que o conteúdo a extrapole ou se oponha a ela.

Segundo Myriam Ávila, três aspectos básicos são importantes para se entender "os limites e as possibilidades" da forma dos limericks: "o ritmo, o esquema de rimas e a economia narrativa" ${ }^{14}$

ritmo do limerick "compõe-se de dois versos de três pés cada, seguidos de um verso de quatro pés (que a rima interna torna desdobrável em dois versos de dois pés) e por fim mais um verso de três pés". ${ }^{15}$ Esse ritmo é extremamente regular em todos esses poemas e "confere na maioria dos casos a organização do conteúdo: cada verso tende a conter uma informação completa, formando uma unidade narrativa". ${ }^{16}$

Quanto às rimas, os cinco versos dos limericks seguem o esquema de rimas aabba, ou seja, o primeiro, o segundo e o quinto verso terminam numa rima, e o terceiro e o quarto noutra.

Os cinco versos (ou quatro) do limerick limitam sua narrativa, que tem de ser "obrigatoriamente" concisa sem "meios-tons". A "brusquidão" com que é contada a estória torna, então, "o limerick um equivalente verbal da caricatura, dando margem ao humor e ao nonsense". ${ }^{17}$

A forma dos limericks é tradicionalmente usada para transmitir uma anedota curta, com o último verso concluindo e comentando o que foi narrado. Nos poemas de Lear, entretanto, não existe uma frase clímax do discurso. $\bigcirc$ último verso, que deveria ser o punch line, remete ao primeiro verso, instaurando a circularidade do poema e excluindo a possibilidade de uma conclusão. De fato, os limericks de Lear "não se resolvem como piada, mantendo eternamente o seu mistério, que é ser e não ser pura literalidade" ${ }^{18}$

Outro aspecto, somado à ilustração e à forma, a se considerar na leitura dos limericks, é o uso do adjetivo no último verso 
AMARANTE, Dirce Waltrick do. Imagem e forma: dois aspectos dos limericks...

do poema. $\bigcirc$ adjetivo de Lear pode ser usado de três maneiras: 1) como um comentário óbvio, aumentando a "redundância do texto"; 2) como um julgamento, classificando como negativa ou positiva uma situação difícil de interpretar, o que deixa o leitor nas mãos do autor; e 3) como um recurso para "aumentar a estranheza de uma situação incomum", para tanto o adjetivo é usado "sem referência ao seu sentido usual e sem conexão com os acontecimentos narrados", ou é uma palavra sem sentido, ou uma palavra composta, ou é aplicado ao protagonista, quando deveria ser aplicado ao fato narrado. ${ }^{19}$

Caberia dizer ainda que a maioria dos limericks "apresenta o nome de um ponto geográfico específico", os demais "se referem a aspectos topográficos ou a pontos cardeais" (There are na old man of Peru, France.../ Havia um velho homem do Peru, França...). A escolha dos lugares de onde provêm os personagens é, todavia, arbitrária. Nos poemas de Lear o esquema "Old person/ lady/man..." (pessoa/dama/homem...velho) é o mais comum, muito raramente "a personagem é classificada como jovem". ${ }^{20}$ Aparecem com freqüência diálogos de caráter "inquisitorial", respostas "não-cooperativas" e gritos, que enfatizam a falta ou a dificuldade de comunicação entre os personagens. ${ }^{21}$

No Brasil, essas e outras características dos poemas humorísticos de Lear podem ser encontradas no livro Adeus, Ponta do Meu Nariz! (Editora Hedra, São Paulo, 2003). Nessa edição bilíngüe, Marcos Maffei traduz 90 limericks de Lear, mantendo, além das ilustrações originais do artista inglês (permitindo ao leitor o acesso ao jogo de significados entre desenho e texto), a forma fixa determinada por Lear e o espírito nonsense de sua poesia, como o uso do adjetivo, à maneira de Lear, no verso final.

Existe ainda uma outra coletânea modesta e talvez esteticamente equivocada dos poemas de Lear em português: trata-se do livro Sem Cabeça nem Pé (Editora Ática, 1992), cuja tradução é assinada pelo poeta José Paulo Paes. Sem Cabeça nem Pé ofere- 
ce ao leitor a tradução de 17 poemas, acompanhados do texto original. No que diz respeito a essa tradução, embora assinada pelo renomado tradutor José Paulo Paes, ela não revela as características nonsense peculiares à poesia de Lear, como, por exemplo, a ausência de um punch line e o cuidado na escolha dos adjetivos. Nesse livro, os desenhos que acompanham o texto são de Luiz Maia, que, percebe-se facilmente, não deu atenção ao diálogo complexo e sutil entre a ilustração e o poema, proposto por Lear .

Além desses dois livros, parece-me não existir outras obras no Brasil que reúnam os poemas humorísticos de Lear.

Contudo, o leitor brasileiro interessado em conhecer melhor o universo nonsense de Edward Lear conta também com o importante ensaio Rima e Solução: A Poesia Nonsense de Lewis Carroll e Edward Lear (Annablume, São Paulo, 1996), de Myriam Ávila, uma introdução à literatura nonsense.

No tocante às minhas traduções, apresentadas no corpo deste artigo e também abaixo, procurei manter nelas alguns dos aspectos acima citados, que considero essenciais para se entender a proposta dos poemas nonsense de Edward Lear.

Para fazer a rima, adaptei o conteúdo de alguns versos, modificando, por exemplo, a "nacionalidade" dos personagens. Procurei dar atenção aos adjetivos dos poemas, tão caros à Lear, e preservar a circularidade do discurso que "se fecha sobre si mesmo, realizando o seu sentido no mero preenchimento da fórmula". ${ }^{22}$

Para exemplificar a discussão acima, seguem-se mais alguns limericks de Lear na minha tradução: 


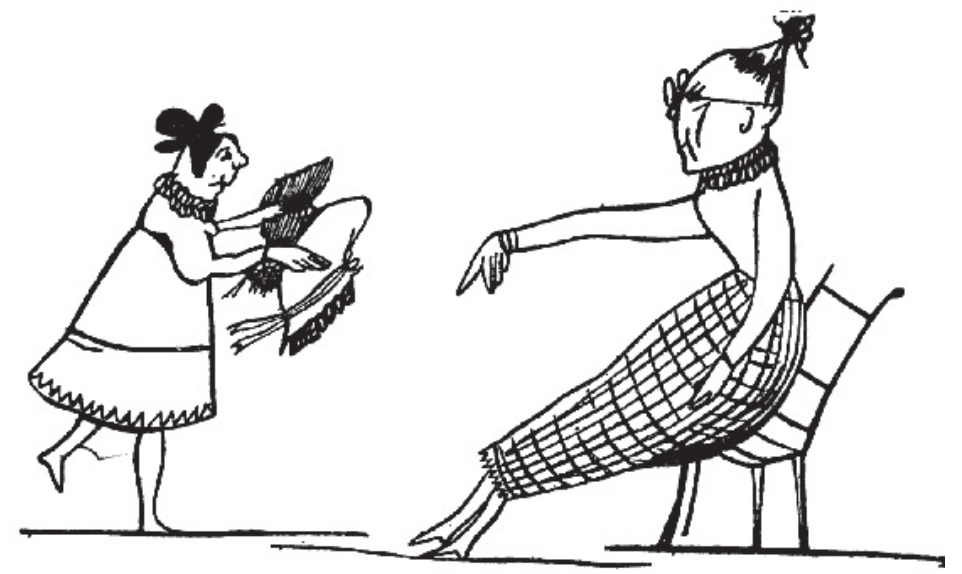

There was an lady of Prague

Havia uma velha dama de Praga,

Cuja linguagem era de todo vaga, quando the diziam, "são toucas, essas que vês?", ela respondia, "talvez"

Essa oracular dama de Praga.

(There was an Old Lady of Prague,/ Whose language was horribly vague;/ When they Said, "Are these caps? she answered, "Perhaps!"/

That oracular Lady of Prague.) 


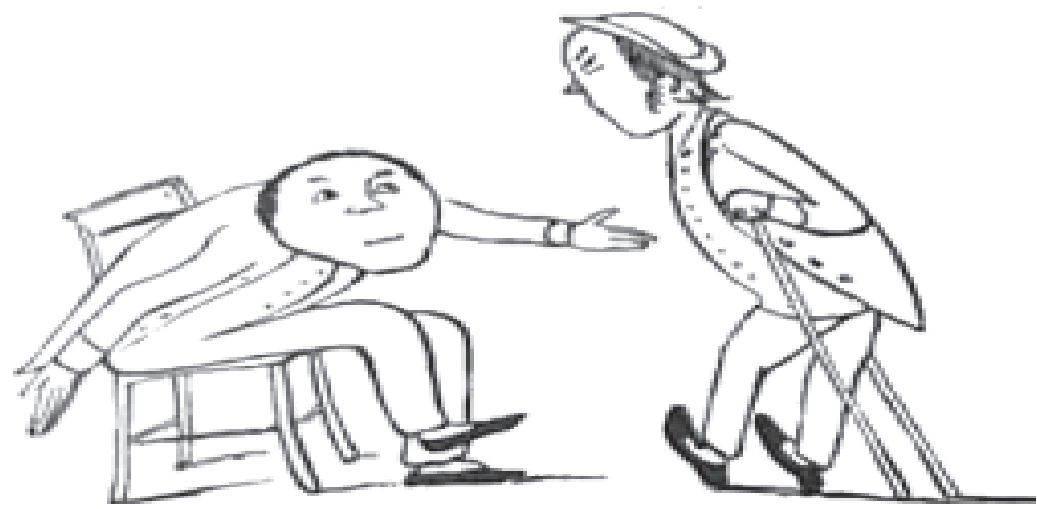

There was an old person Deal

Havia um velho cidadão de Dacar,

Que caminhava na ponta do calcanhar;

Quando lhe perguntavam, "A troco de quê??", ele não revelava o por quê, Esse cidadão misterioso de Dacar.

(There was an old person of Deal,/ Who in walking used only his heel;/ When they said, "Tell us why? he made no reply,/ That mysterious old person of Deal.) 


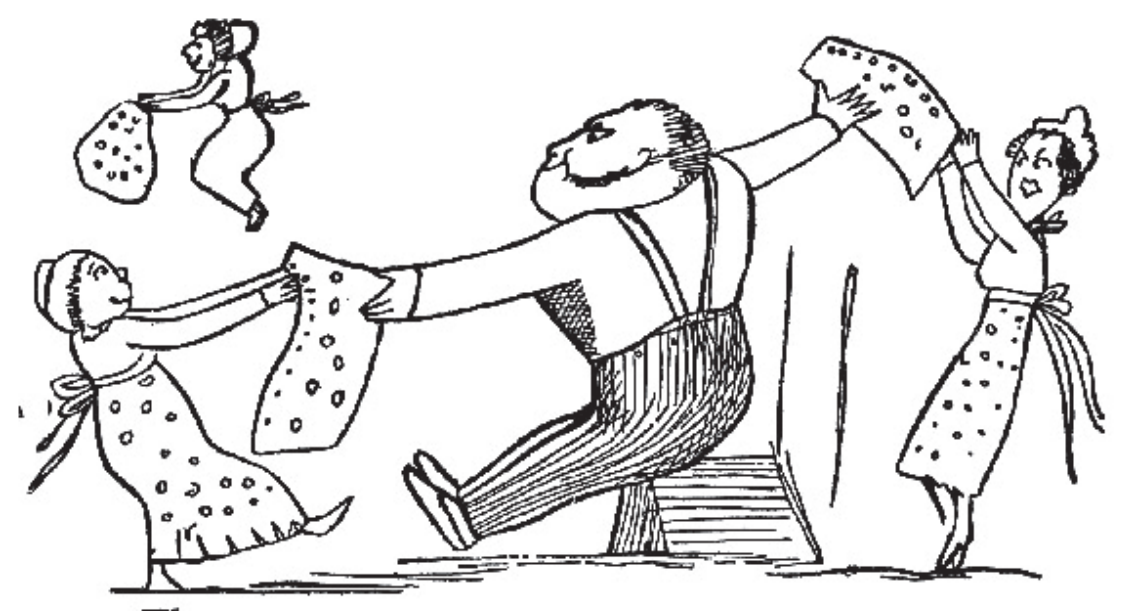

There was an old man in a pew

Havia um Velho Senhor num banco de igreja,

Cujo colete tinha pontos cor de cereja;

Mas ele o cortou em partes miúdas, para doá-los às viúvas,

Esse agradável Senhor num banco de igreja.

(There was an Old Man in a pew, / Whose waistcoat was spotted with blue;/ But he tore it in pieces, to give to his Nieces,/ That cheerful Old Man in a pew.) 


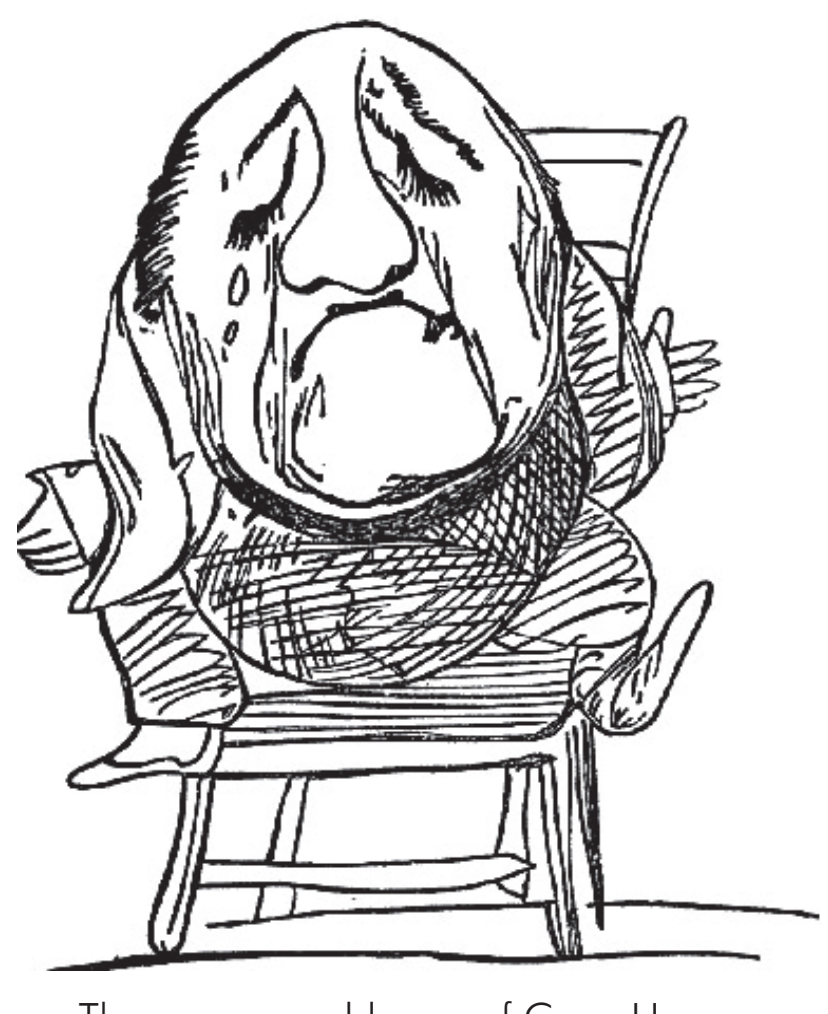

There was an old man of Cape Horn

Havia um Velho Senhor do Rio Comprido,

Que desejou nunca ter nascido;

Então se sentou num manto até se esvair em pranto, Esse lastimoso Senhor do Rio Comprido.

(There was an Old Man of Cape Horn, / Who wished he had never been born;/ So he sat on a Chair till he died of despair,/ That dolorous Man of Cape Horn.) 


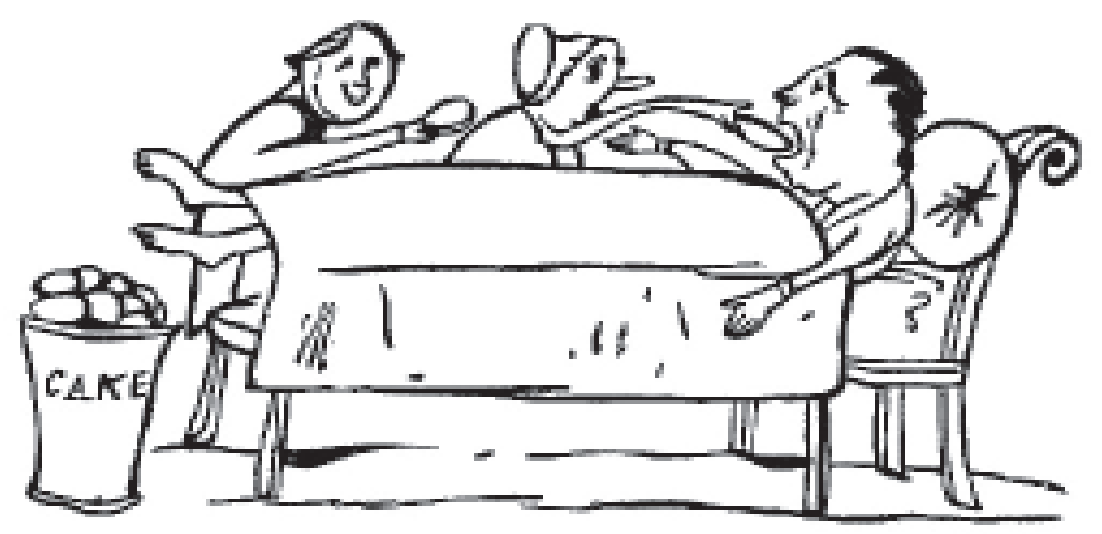

There was an old person of Rheims

Havia um Velho Cidadão de Quito

Cujos sonhos o deixavam aflito;

Para mantê-lo acordado, davam-lhe pão com melado,

E deleitavam esse Cidadão de Quito.

(There was an Old Person of Rheims, / Who was troubled with horrible dreams;/ So to keep him awake they fed him with cake,/ Which amused that Old Person of Rheims.)

\section{NOTAS}

1 LEAR, Edward. Adeus, Ponta do Meu Nariz!. Organização e tradução: Marcos Maffei. São Paulo: Hedra, 2003, p. 112.

2 As traduções de limericks, neste ensaio, são todas de minha autoria. $\bigcirc$ limerick citado foi escolhido ao acaso, não significa, por isso, que tenha sido um daqueles escritos por Lear em Knowsley Hall.

3 LEAR, Edward. Op. Cit., p. 106.

4 ÁVILA, Myriam. Rima e Solução: A Poesia Nonsense de Lewis Carroll e Edward Lear. São Paulo: Annablume, 1996, p. 65.

5 STEWART, Susan. Nonsense: Aspects of Intertextuality in Folklore and Literature. Baltimore e Londres: The Johns Hopkins University Press, 1989, p. 167.

6 LEAR, Edward. Op. Cit., p. 125. 
Cadernos de Literatura em Tradução, n. 6, p. 45-59

7 idem, p. 138

8 EDE, Lisa. "Edward Lear's Limericks and their Illustrations", in TIGGES, Wim (org.). Explorations in the Field of Nonsense. Amsterdã: Rodopi, 1987, p. 104.

9 idem ibidem.

10 idem, p. 110

11 idem ibidem. A respeito das metamorfoses, Myriam Ávila opina que "o mimetismo é de mão dupla". No entanto, os animais mantêm sua natureza, por isso jamais falam e quando emitem sons são aqueles naturais de sua espécie. ÁVILA, Myriam. Op. Cit., p. 76.

12 EDE, Lisa. Op. Cit., p. 115.

13 ÁVILA, Myriam. Op. Cit., p. 61.

14 idem, p. 65.

15 idem ibidem.

16 ÁVILA, Myriam. Op. Cit., p. 66.

17 idem ibidem.

18 idem, p. 67.

19 ÁVILA, Myriam. Op. Cit., p. 69, 70.

20 Idem, p. 69

21 idem, p. 81

22 idem, p. 77. 